\title{
Viscosity-temperature relationships in the system $\mathrm{Na}_{2} \mathrm{Si}_{2} \mathrm{O}_{5}-\mathrm{Na}_{4} \mathrm{Al}_{2} \mathrm{O}_{5}$
}

\author{
DONALD B. DingWell \\ Geophysical Laboratory, Carnegie Institution of Washington, 2801 Upton St. N.W., Washington, D.C. 20008, U.S.A.
}

(Received December 10, 1985; accepted in revised form March 17, 1986)

\begin{abstract}
The viscosity-temperature relationships of five melts on the join $\mathrm{Na}_{2} \mathrm{Si}_{2} \mathrm{O}_{5}-\mathrm{Na}_{4} \mathrm{Al}_{2} \mathrm{O}_{5}(5,10,20$, 30 and 40 mole percent $\mathrm{Na}_{4} \mathrm{Al}_{2} \mathrm{O}_{5}$ ) have been measured in air, at 1 atm and $1000-1350^{\circ} \mathrm{C}$ with a concentric cylinder viscometer. All the melts on this join of constant bulk polymerization behave as Newtonian fluids, in the range of shear rates investigated, and the melts exhibit Arrhenian viscosity-temperature relationships. Isothermal viscosities on this join initially decrease and then increase with increasing mole percent $\mathrm{Na}_{4} \mathrm{Al}_{2} \mathrm{O}_{5}$. The minimum viscosity occurs near 20 mole percent $\mathrm{Na}_{4} \mathrm{Al}_{2} \mathrm{O}_{5}$ at $1000^{\circ} \mathrm{C}$ and moves to higher $\mathrm{Na}_{4} \mathrm{Al}_{2} \mathrm{O}_{5}$ content with increasing temperature.

The observation of a viscosity minimum along the join $\mathrm{Na}_{2} \mathrm{Si}_{2}-\mathrm{O}_{5}-\mathrm{Na}_{4} \mathrm{Al}_{2} \mathrm{O}_{5}$ is not predicted based on earlier viscosity data for the system $\mathrm{Na}_{2} \mathrm{O}-\mathrm{Al}_{2} \mathrm{O}_{3}-\mathrm{SiO}_{2}$ (RIEBLING, 1966) or based on calculation methods derived from this and other data (BOTTINGA and WEILL, 1972). This unexpected behavior in melt viscositytemperature relations emphasizes the need for a more complete data set in simple silicate systems.

Previous spectroscopic investigation of melts on the join $\mathrm{Na}_{2} \mathrm{Si}_{2} \mathrm{O}_{5}-\mathrm{Na}_{4} \mathrm{Al}_{2} \mathrm{O}_{5}$ offer a structural explanation for the observed viscosity data in terms of a disproportionation reaction involving polyanionic units. Macroscopically, the viscosity data may be qualitatively reconciled with the configurational entropy model for viscous flow (RICHET, 1984).
\end{abstract}

\section{INTRODUCTION}

THE DEVELOPMENT OF a quantitative, structurally based relationship between the composition and viscosity of aluminosilicate melts is dependent on a fundamental understanding of the mechanism of viscous flow in such melts. The ternary system $\mathrm{Na}_{2} \mathrm{O}-\mathrm{Al}_{2} \mathrm{O}_{3}$ $\mathrm{SiO}_{2}$ is a relatively well-investigated system in terms of both viscosity (RIEBLING, 1966, HUNOLD and BRUCKNER, 1979) and structure (TAYLOR and BROWN, 1979; MCMILLAN et al., 1982; NAVROTSKY et al., 1982; SEIFERT et al., 1982). This system also pertains to two important compositional parameters in the petrochemistry of rocks of the granitic and felsic alkaline associations, namely the $\mathrm{Al} /(\mathrm{Al}+\mathrm{Si})$ and alkali/aluminum ratios. Along joins of constant $\mathrm{SiO}_{2}$ content, aluminum-saturated melts [ $\mathrm{Na} / \mathrm{Al}($ molar $)=1]$ have higher viscosities and activation energies of viscous flow than either aluminum-oversaturated (peraluminous) or aluminum-undersaturated (peralkaline) melts (RIEBLING, 1966, HUNOLD and BRUCKNER, 1979).

Previous studies of the viscosity and structure of melts along the join $\mathrm{NaAlO}_{2}-\mathrm{SiO}_{2}$ have provided an important insight into the effect of the substitution of aluminate for silicate tetrahedra on the viscosity of fully polymerized melts. The effect of this substitution on the viscosity of depolymerized melts, however, remains uninvestigated. Melts on the join $\mathrm{Na}_{2} \mathrm{Si}_{2} \mathrm{O}_{5}-\mathrm{Na}_{4} \mathrm{Al}_{2} \mathrm{O}_{5}$ and $\mathrm{SiO}_{2}-\mathrm{NaAlO}_{2}$ are parallel in molar projection (Fig. 1). They have constant bulk polymerization (NBO/T) values equal to 1 and 0 , respectively. NBO/T represents the ratio of nonbridging oxygens to tetrahedrally coordinated cations and the method of calculation of $\mathrm{NBO} / \mathrm{T}$ has been discussed by MYSEN et al. (1982). Thus, the join $\mathrm{Na}_{2} \mathrm{Si}_{2} \mathrm{O}_{5}-\mathrm{Na}_{4} \mathrm{Al}_{2} \mathrm{O}_{5}$ provides a useful basis for comparison with the join $\mathrm{NaAlO}_{2}-\mathrm{SiO}_{2}$ be- cause these joins represent the substitution $\mathrm{NaAl} \rightleftharpoons \mathrm{Si}$ in depolymerized and polymerized melts, respectively.

\section{EXPERIMENTAL}

The compositions investigated in this study lie along the compositional join $\mathrm{Na}_{2} \mathrm{Si}_{2} \mathrm{O}_{5}-\mathrm{Na}_{4} \mathrm{Al}_{2} \mathrm{O}_{5}$, denoted NS-NA (Fig. 1). This study presents viscosity-temperature relationships for melts of composition (mole percent) $\mathrm{NS}_{95} \mathrm{NA}_{5}, \mathrm{NS}_{90} \mathrm{NA}_{10}$. $\mathrm{NS}_{80} \mathrm{NA}_{20}, \mathrm{NS}_{70} \mathrm{NA}_{30}$ and $\mathrm{NS}_{60} \mathrm{NA}_{40}$, abbreviated NSNA5, NSNA 10, NSNA20, NSNA30 and NSNA40, respectively, in the following discussion.

The starting materials for viscosity determinations were glasses prepared from reagent grade $\mathrm{Na}_{2} \mathrm{CO}_{3}, \mathrm{Al}_{2} \mathrm{O}_{3}$ and purified quartz sand. Mixtures of the sodium carbonate, alumina and quartz equivalent to a decarbonated weight of $50 \mathrm{~g}$ were ground under alcohol in an agate mortar for 3 hours and then decarbonated at $800^{\circ} \mathrm{C}$ overnight. The decarbonated samples were fused at $1350^{\circ} \mathrm{C}$ for 3 hours in a $25 \mathrm{~cm}^{3} \mathrm{Pt}$ crucible Prior to viscosity determinations, fused samples were poured from the $\mathrm{Pt}$ crucible into the $\mathrm{Pt}_{80} \mathrm{Rh}_{20}$ crucibles used for viscosity determinations and stirred with a $\mathrm{Pt}_{80} \mathrm{Rh}_{20}$ spindle for I hour at $1350^{\circ} \mathrm{C}$ resulting in homogeneous, bubble-free melts.

Viscosities were measured at $1 \mathrm{~atm}$ in the temperature range $1350-1000^{\circ} \mathrm{C}$ with the concentric cylinder method. The samples were contained in cylindrical $\mathrm{Pt}_{80} \mathrm{Rh}_{20}$ crucibles $(5.1 \mathrm{~cm}$ long, $2.56 \mathrm{~cm}$ inner diameter, $0.1 \mathrm{~cm}$ wall thickness) in a $\mathrm{SiC}$ heated vertical tube furnace (Fig. 2). Temperatures were monitored during viscosity runs with a $\mathrm{Pt}_{90} \mathrm{Rh}_{10}$ thermocouple (calibrated against the melting of $\mathrm{Au}$ at $1064^{\circ} \mathrm{C}$ ) in ceramic insulation. The thermocouple was recessed into a $0.2 \mathrm{~cm}$ vertical groove in the firebrick cradle adjacent to the sample crucible (Fig. 2). In addition, the sample temperature was checked by immersing a shielded (in platinum tubing) $\mathrm{Pt}_{90} R \mathrm{~h}_{10}$ thermocouple in the melt at the high and low temperature extremes of each viscosity run. There was a reproducible $5^{\circ} \mathrm{C}$ difference between the temperatures recorded by the permanent and immersed thermocouples due to a radial temperature gradient outside the crucible. There were no significant $\left(>1^{\circ} \mathrm{C}\right)$ temperature gradients inside the sample crucible. The vertical temperature profiles from immersion and furnace thermocouples are shown in Fig. 2. The temperatures reported in this study are accurate to $\pm 2^{\circ} \mathrm{C}$. 


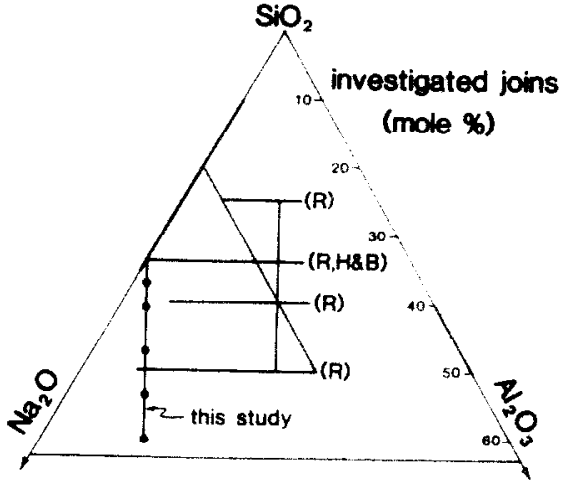

FIG. 1. Starting compositions for this study and previously investigated joins in the system $\mathrm{Na}_{2} \mathrm{O}-\mathrm{Al}_{2} \mathrm{O}_{3}-\mathrm{SiO}_{2}$. [(R) $=$ RIEBLING, 1966; $(\mathrm{H} \& B)=$ HUNOLD and BRUCKNER, 1979] The diagram is in mole percent

Viscosities were measured with a Brookfield RVTD viscometer head. This viscometer head drives a spindle at a range of constant speeds $(0.5$ to $100 \mathrm{rpm})$ and digitally records the torque exerted on the spindle by the sample. The $\mathrm{Pt}_{80} \mathrm{Rh}_{20}$ spindle used in this study has the cross-section of a cylinder (1.44 cm diameter, $3.32 \mathrm{~cm}$ length) with $45^{\circ}$ conical ends to reduce end effects and a $0.24 \mathrm{~cm}$ diameter stem.

The spindle and head were calibrated for viscosity measurement with the NBS SRM 711 Lead-silica glass for which the viscosity-temperature relationship is accurately known. The precision and accuracy of viscosity data are based on the observed precision during replicate measurements of the standard glass SRM 711. Six determinations of the viscosity of SRM 711, each involving re-occupation of the temperature setting and removal and reinsertion of the measuring spindle gave a standard deviation $(1 \sigma)$ equal to $1.5 \%$. The precision of determinations is quoted at $\pm 3 \%(2 \sigma)$. The accuracy of determinations is taken as the sum of the uncertainties from standard and sample determinations, equal to $\pm 6 \%(2 \sigma)$.

For each sample, the viscosity measurements were made at the highest temperature and then at successively lower temperatures. Thermal equilibrium was monitored with a chart recording of the sample viscosity during the decreasing tem-

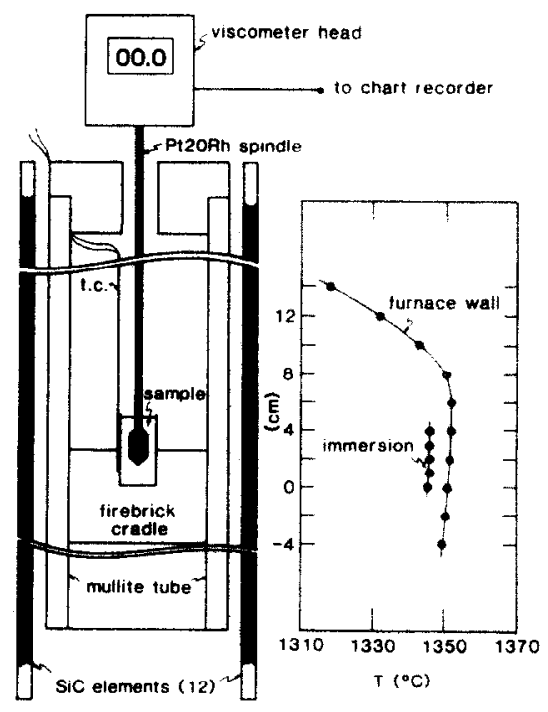

FIG. 2. The experimental apparatus used in the present study. (schematic except for vertical scale)
Table 1. Analyaed melt compositions.

\begin{tabular}{|c|c|c|c|c|}
\hline SAMPLE & $\mathrm{Na}_{2} \mathrm{O}$ & $\mathrm{Al}_{2} \mathrm{O}_{3}$ & $\mathrm{SiO}_{2}$ & $M_{4}$ \\
\hline NSNAS & $\begin{array}{c}35.1 \\
(35.30)\end{array}$ & $\left\{\begin{array}{l}2,8 \\
\{2,77\}\end{array}\right.$ & $\begin{array}{c}62.4 \\
(61.93)\end{array}$ & 100.3 \\
\hline NSNA 10 & $\begin{array}{l}36.4 \\
(36.35)\end{array}$ & 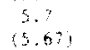 & $\begin{array}{l}57.6 \\
\{57.98:\end{array}$ & $3:$ \\
\hline NSNA2O & $\begin{array}{c}38.7 \\
(38.96)\end{array}$ & $\begin{array}{c}10.6 \\
(10.68)\end{array}$ & $\begin{array}{l}50.3 \\
(50.36\end{array}$ & 34,0 \\
\hline NSNA 30 & $\begin{array}{c}39.0 \\
(41.26)\end{array}$ & $\begin{array}{l}15.8 \\
(15.66\end{array}$ & $\begin{array}{c}43.3 \\
(43.07\end{array}$ & 43.1 \\
\hline NSNA40 & $\begin{array}{c}42.1 \\
(42.70)\end{array}$ & $\begin{array}{l}20.5 \\
20.70\}\end{array}$ & $\begin{array}{l}36.7 \\
36.60\end{array}$ & $20:$ \\
\hline
\end{tabular}

Analysts: J. Marinenko, $H$, Smith, USGS Reserar,

VA. Na \& Al by ICP, Si by gravimetry.

(precision: elements less than $10 z$ equal

2-10z rel.; elements greater than $10 \%$ equal.

$1-27$ re $1 .$. S 10 equals 0.12 abs.)

Numbers in brackets are stoichtometri.. positions.

perature steps of approximately $50^{\circ} \mathrm{C}$. One hour was suffictent for thermal equilibration of the sample over each 50 to $100^{\circ} \mathrm{C}$ temperature decrease. At the termination of each viscosity run, a high temperature viscosity measurement was redetermined to check for instrumental drift during a run. No drift was observed for any of these samples.

Torque measurements were made over a range of shear rates (i.e., rotation speeds) for each sample. In all cases, the viscosities obtained were independent of shear rate. Samples were poured from the crucibles at the termination of each run and analysed by inductively coupled plasma for $\mathrm{Na}_{2} \mathrm{O}$ and $\mathrm{Al}_{2} \mathrm{O}_{3}$ and by gravimetry for $\mathrm{SiO}_{2}$. Glass homogeneity was checked by microprobe analysis of several chips of each glass. The chemical analyses are presented in Table 1

\section{RESULTS}

The results of the viscosity determinations are presented in Table 2 and are plotted versus reciprocal absolute temperature in Fig. 3. All compositions exhibil viscosity-temperature relationships that may be fitted. within error, to the Arrhenius relationship.

$$
\log _{10} \eta=\log _{10} \eta_{0}+E_{\eta} / 2.303 R 7
$$

where $\eta$ is the viscosity at temperature $T, \log _{10} \eta_{0}$ is the pre-exponential or frequency factor. $R$ is the gas constant and $E \eta$ is the activation energy of viscous flow. The Arrhenius parameters, $\log _{10} \eta_{0}$ and $E \eta$ are included in Table 2. The viscosity of sodium disilicate melt (denoted NS in text and Fig. 3) in the temperature range of this study has been investigated by several workers and the results of studies by LILLIE (1939). MEILING; and UHLMANN (1967) and FONTANA and PLUMMER. (1979) are included in Fig. 3 along with a least squares fit to all the sodium disilicate data. It is evident from the data in Fig. 3 that the viscosity-temperature relationships of melts on the join NS-NA exhibit a decreasing bulk viscosity with increasing NA content to composition NSNA20 and an increasing bulk viscosity beyond this composition. The activation energies $E_{\eta}$ of the melts (as defined by the slopes in Fig. 3) are constant (within error) from sodium disilicate to NSNA20 and then increase to NSNA40. The frequency factors $\left(\log _{10} \eta_{0}\right.$; vertical intercepts in Fig. 3) decrease from NSNA5 to NSNA40. The isothermal viscosities along the NS-NA join obtained by $50^{\circ} \mathrm{C}$ interpolations of the data of Table 2 (Fig. 4) show a minimum near NSNA30 at $1350^{\circ} \mathrm{C}$. This minimum moves towards 
Table 2. Viscosity data and derived Arrhentan parameters.

\begin{tabular}{|c|c|c|c|c|c|c|c|c|c|}
\hline $\mathrm{T}\left({ }^{\circ} \mathrm{C}\right)$ & $\log _{10^{n}}$ & $\mathrm{~T}\left({ }^{\circ} \mathrm{C}\right)$ & $\log _{10} n$ & $\mathrm{~T}\left({ }^{\circ} \mathrm{C}\right)$ & $\log _{10^{n}}$ & $T\left({ }^{\circ} \mathrm{C}\right)$ & $\log _{10^{n}}$ & $T\left({ }^{\circ} \mathrm{C}\right)$ & $\log _{10^{n}}$ \\
\hline 1350 & 1.63 & 1330 & 1.59 & 1345 & 1.46 & 1314 & 1.51 & 1348 & 1.55 \\
\hline 1300 & 1.78 & 1280 & 1.75 & 1287 & 1.64 & 1229 & 1.85 & 1315 & 1.65 \\
\hline 1255 & 1.96 & 1235 & 1.92 & 1240 & 1.82 & 1178 & 2.06 & 1294 & 1.78 \\
\hline 1200 & 2.14 & 1185 & 2.11 & 1190 & 2.00 & 1130 & 2.27 & -- & -- \\
\hline 1150 & 2.34 & 1140 & 2.30 & 1142 & 2.20 & 1076 & 2.53 & -- & -- \\
\hline 1105 & 2.55 & 1085 & 2.55 & 1095 & 2.41 & 1029 & 2.78 & - & -- \\
\hline 1055 & 2.78 & 1035 & 2.76 & 1048 & 2.66 & 979 & 3.07 & -- & - \\
\hline 1008 & 3.02 & 995 & 2.93 & 995 & 2.93 & -- & -- & - & -- \\
\hline \multicolumn{2}{|c|}{$E_{n} 37.3 \pm 0.7$} & \multicolumn{2}{|c|}{$38.4 \pm 1.2$} & \multicolumn{2}{|c|}{$38.3 \pm 1.6$} & \multicolumn{2}{|c|}{$42.7 \pm 0.7$} & \multicolumn{2}{|c|}{$49.1 \pm 3.0$} \\
\hline \multicolumn{2}{|c|}{$\mathrm{PF}-3.4 \pm 0.1$} & \multicolumn{2}{|c|}{$-3.7 \pm 0.2$} & \multicolumn{2}{|c|}{$-3.7 \pm 0.2$} & \multicolumn{2}{|c|}{$-4.4 \pm 0.1$} & \multicolumn{2}{|c|}{$-5.1 \pm 0.4$} \\
\hline
\end{tabular}

Is the arrhenian activation energy, PF is the pre-exponentlal factor. Temperatures are $\pm 2^{\circ} \mathrm{C} ; v 1$ cosities are $\pm 6 z$ at $2 \mathrm{std}$. dev.

higher sodium disilicate content with decreasing temperature.

\section{DISCUSSION}

\section{Previous work}

Discussion of these data is facilitated by comparison with the results of previous investigations of melt viscosities in the system $\mathrm{Na}_{2} \mathrm{O}-\mathrm{Al}_{2} \mathrm{O}_{3}-\mathrm{SiO}_{2}$ (as indicated in Fig. 1). RIEBLING (1966) measured the viscosities of melts along joins of constant $\mathrm{SiO}_{2}$ content, constant $\mathrm{Na}_{2} \mathrm{O}$ content and constant $\mathrm{Na} / \mathrm{Al}$ ratio. The only other join of constant bulk polymerization $(\mathrm{NBO} / \mathrm{T}=0$ ) that has been investigated in this system is $\mathrm{SiO}_{2}-\mathrm{NaAlO}_{2}$ (RIEBLING, 1966). No viscosity minima have been observed along previously investigated binary joins in the system $\mathrm{Na}_{2} \mathrm{O}-\mathrm{Al}_{2} \mathrm{O}_{3}-\mathrm{SiO}_{2}$ and there is no indication from the pre-existing data base that a minimum in viscosity would occur on the join $\mathrm{Na}_{2} \mathrm{Si}_{2} \mathrm{O}_{5}-\mathrm{Na}_{4} \mathrm{Al}_{2} \mathrm{O}_{5}$.

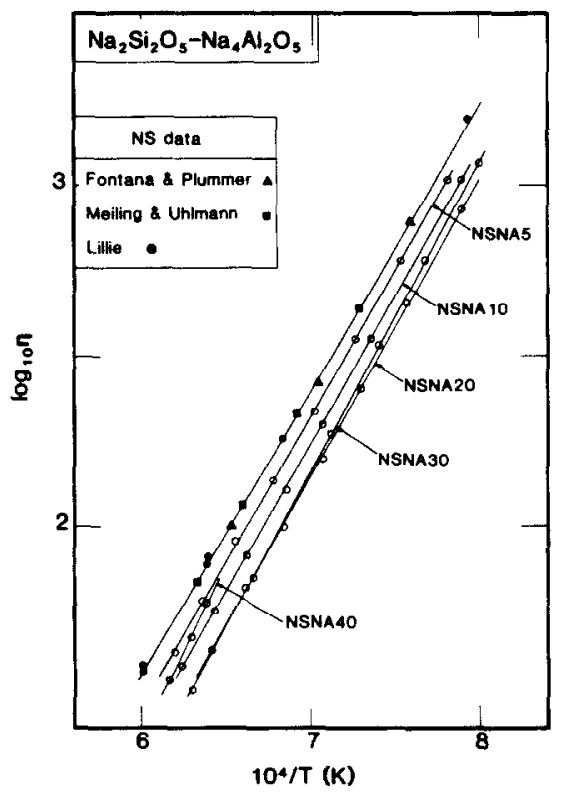

FIG. 3. Viscosity-temperature relationships for melts on the join $\mathrm{Na}_{2} \mathrm{Si}_{2} \mathrm{O}_{5}-\mathrm{Na}_{4} \mathrm{Al}_{2} \mathrm{O}_{5}$. Sodium disilicate data are from Fontana and Plummer (1966) (triangles), MEILING and UHLMANN (1967) (squares) and LILLIE (1939) (solid circles).
In this regard it is important to note that all the data of RiEBLING (1966) and HUNOLD and BRUCKNER (1979) are for melts containing at least 50 mole $\% \mathrm{SiO}_{2}$. With the new data presented in this study it is tempting to speculate on the possibility of a viscosity minimum on the join $\mathrm{SiO}_{2}-\mathrm{NaAlO}_{2}$.

Considering the limited composition range of previous data it is not surprising that the calculation method of BOTTINGA and WEILL (1972) (based on the data of RIEBLING, 1966 and others) does not predict a viscosity minimum on the join $\mathrm{Na}_{2} \mathrm{Si}_{2} \mathrm{O}_{5}-\mathrm{Na}_{4} \mathrm{Al}_{2} \mathrm{O}_{5}$. Figure 4 compares the calculated and measured viscosities for the join $\mathrm{Na}_{2} \mathrm{Si}_{2} \mathrm{O}_{5}-\mathrm{Na}_{4} \mathrm{Al}_{2} \mathrm{O}_{5}$. Good agreement is found for sodium disilicate to NSNA30. The calculations fail for NSNA40. This discrepancy at NSNA40 is probably due to the lack of data for $\mathrm{NaAlO}_{2}$-bearing melts in the compositional interval of mole fraction $\mathrm{SiO}_{2}=0.35-0.45$, as noted by BOTTINGA and WEILL (1972).

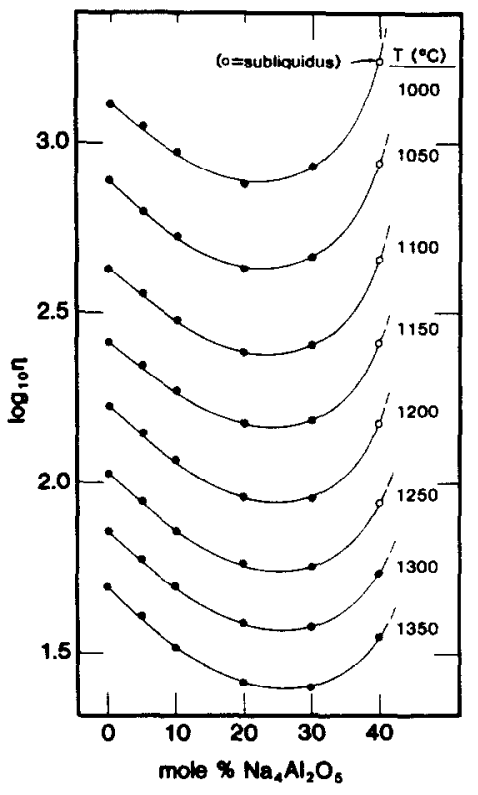

Fig. 4. Isothermal viscosities of melts on the join $\mathrm{Na}_{2} \mathrm{Si}_{2} \mathrm{O}_{5}$ $\mathrm{Na}_{4} \mathrm{Al}_{2} \mathrm{O}_{5}$. (Solid circles represent interpolations at $50^{\circ} \mathrm{C}$ intervals, open circles represent extrapolations.) 
More significant for the present study, however, is the observation that the BOTTINGA and WEILL (1972) method does not reproduce the smooth trend of melt viscosity reported in this study (Fig. 5, inset). Again, BOTTINGA and WEILL (1972) anticipate such difficulties due to the fact that their method was based on a variation of the logarithm of viscosity with composition fitted over discrete composition ranges. The compositions of this study vary greatly in silica content and thus highlight the discontinuities observed when using the BOTTINGA and WEILL (1972) method over large ranges of silica content.

\section{Melt structure}

Melts on the join $\mathrm{SiO}_{2}-\mathrm{NaAlO}_{2}$ consist of a continuous three-dimensional network of silicate and aluminate tetrahedra with each tetrahedrally coordinated Al charge balanced by a neighbouring $\mathrm{Na}$ atom (TAYLOR and BROWN, 1979; NAVROTSKY et ul., 1982; SEIFERT et al., 1982). Accordingly, the observation of decreasing viscosity and activation energy with decreasing $\mathrm{SiO}_{2}$ content along this join has been interpreted in terms of a decrease in the average strength of bridging bonds that must be broken for viscous flow in these melts (MYSEN et al., 1980). Viscosity and activation energy decrease strongly from $\mathrm{SiO}_{2}$ to $3 \mathrm{SiO}_{2} \cdot \mathrm{NaAlO}_{2}$ (albite), but activation energies decrease only slightly from $3 \mathrm{SiO}_{2} \cdot \mathrm{NaAlO}_{2}$ (albite) to $\mathrm{SiO}_{2} \cdot \mathrm{NaAlO}_{2}$ (nepheline).

Melts on the joins $\mathrm{Na}_{2} \mathrm{Si}_{3} \mathrm{O}_{7}-\mathrm{NaAlSi}_{3} \mathrm{O}_{8}$ (RIEBLING, 1966), $\mathrm{Na}_{2} \mathrm{Si}_{2} \mathrm{O}_{5}-\mathrm{NaAlSi}_{2} \mathrm{O}_{6}$ (RIEBLING, 1966; HUNOLD and BRUCKNER, 1979) and $\mathrm{Na}_{2} \mathrm{SiO}_{4}-\mathrm{NaAlSiO}_{4}$ (RIEBLING, 1966) (all at constant $\mathrm{SiO}_{2}$ content) exhibit increasing viscosity and activation energy with increasing Al content. These rapid increases in viscosity and activation energy results from polymerization of the melt structure due to the transfer of sodium atoms from network-modifying coordination of silicate tetrahedra to network-stabilizing coordination of aluminate tetrahedra (SEIFERT et al., 1982). Structural interpretation of the role of aluminate tetrahedra in determining the viscosity of melts along these joins is, however, com-

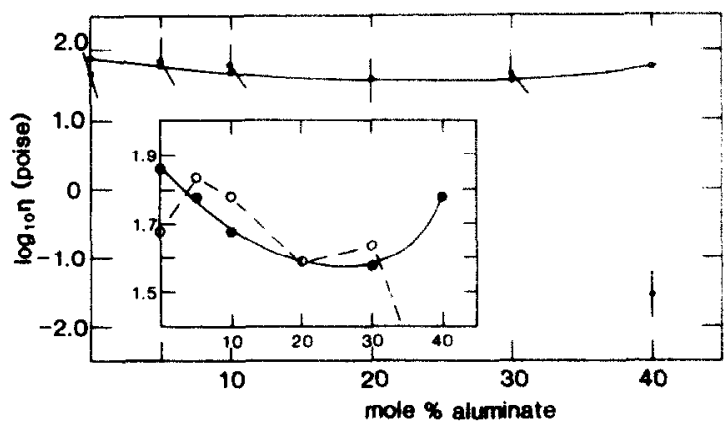

FIG. 5. Comparison of the measured (solid circles) and calculated (open circles) viscosities of melts on the join $\mathrm{Na}_{2} \mathrm{Si}_{2} \mathrm{O}_{5-}$ $\mathrm{Na}_{4} \mathrm{Al}_{2} \mathrm{O}_{5}$. (Data at $1300^{\circ} \mathrm{C}$, calculations using the method of BOTTINGA and WEILL, 1972) plicated by the fact that bulk polymerization (NBO/ $\mathrm{T})$ and $\mathrm{Al} /(\mathrm{Al}+\mathrm{Si})$ are varying simultaneously.

In contrast, melts on the join $\mathrm{Na}_{2} \mathrm{Si}_{2} \mathrm{O}_{5}-\mathrm{Na}_{4} \mathrm{Al}_{2} \mathrm{O}_{5}$ maintain a bulk polymerization of $\mathrm{NBO} / \mathrm{T}=1 \mathrm{re}-$ gardless of aluminum content. Based on the variation of viscosity with composition on the parallel (in molar projection, Fig. 1) join $\mathrm{NaAlO}_{2}-\mathrm{SiO}_{2}$, a continuous decrease in bulk viscosity with increasing aluminum might be expected. In fact, the viscosity and activation energy of melts on the join sodium disilicate-sodium dialuminate do not vary in a manner consistent with the simple replacement of silicate by aluminate tetrahedra. Instead, the minimum in viscosity (Fig. 3) and the increase in activation energy (Table 2), with increasing $\mathrm{Na}_{4} \mathrm{Al}_{2} \mathrm{O}_{5}$ content may result from a structural reorganization of the aluminosilicate anions in response to the chemical exchange, $\mathrm{NaAl}=\mathrm{Si}$.

The structures of melts on the join sodium disilicatesodium dialuminate have been investigated recently (MYSEN et al., 1985). The Raman spectra of quenched melts of sodium disilicate. NSNA5, NSNA10, NSNA20 and NSNA30 show systematic variations in the positions and relative intensity of several peaks.

MYSEN et al. (1985) used the statistical deconvolution procedure developed by SEIFERT et al. (1981) and estimates of the scattering efficiency of the Si-O symmetric stretch in ortho-, meta- and disilicate anionic units to estimate the relative proportions of anionic units in these melts. The resulting variations in polyanionic proportions were attributed to a disproportionation reaction of the type:

$$
\mathrm{Si}_{2} \mathrm{O}_{5}^{2-}+(\mathrm{NaAl})_{2} \mathrm{O}_{5}^{2-}=2 \mathrm{SiO}_{3}^{2-}+2 \mathrm{NaAlO}_{2}
$$

(MYSEN et al. 1985). The disilicate units of intermediate polymerization $(\mathrm{NBO} / \mathrm{T}=1)$ are disproportionated into more and less polymerized units, $i . \epsilon_{\text {.. tecto- }}$ $(\mathrm{NBO} / \mathrm{T}=0)$ and metasilicate $(\mathrm{NBO} / \mathrm{T}-2)$ units. respectively.

RICHET (1984) has recently reviewed the configurational entropy theory of viscous flow of ADAM and GIBBS (1965) as applied to silicate melts. This theory states that there is an inverse correlation between the configurational entropy and viscosity of melts. RICHET and BotTINGA (1984) have shown that some features of the composition-dependence and temperature-dependence of viscosity of some melt systems may be qualitatively understood in terms of the number of energetically equivalent rearrangements recorded by the configurational entropy of the melt system. In the absence of thermodynamic data for $\mathrm{Na}_{4} \mathrm{Al}_{2} \mathrm{O}_{5}$ melt and in view of the Arrhenian behavior observed over the temperature range of this study, a quantitative evaluation of the configurational entropy theory of viscous flow is not attempted here. Low temperature viscosity data are required to constrain the configurational entropy theory parameters. Qualitatively, the position and magnitude of the viscosity minimum with respect to the endmembers is explicable in terms of the configurational entropy theory in which the contribution of 
the entropy of mixing becomes larger with decreasing temperature.

\section{CONCLUSION}

The viscosity-temperature relationships of melts on the join $\mathrm{Na}_{2} \mathrm{Si}_{2} \mathrm{O}_{5}-\mathrm{Na}_{4} \mathrm{Al}_{2} \mathrm{O}_{5}$ exhibit a minimum at a temperature-dependent intermediate composition. The increase in viscosity with increasing aluminate content beyond this intermediate composition is not predicted by calculation methods derived from the pre-existing data base. This failure illustrates the need for a more complete data base on the viscosities of relatively simple silicate melts.

The behavior of viscosity along the join $\mathrm{Na}_{2} \mathrm{Si}_{2} \mathrm{O}_{5}$ $\mathrm{Na}_{4} \mathrm{Al}_{2} \mathrm{O}_{5}$ may reflect the progress of a disproportionation reaction involving di-, meta- and tectosilicate polyanionic units. The viscosity data are qualitatively consistent with the configurational entropy theory of viscous flow.

Acknowledgements-B. Lipin kindly arranged for the chemical analyses of the melts. Jim Dickinson, Bob Luth, Bjorn Mysen, Pascal Richet, David Virgo, and Hatten S. Yoder, Jr. provided useful criticisms.

\section{Editorial handling: F. Albarede}

\section{REFERENCES}

ADAM G. and GiBBS J. H. (1965) On the temperature dependence of cooperative relaxation properties in glassforming liquids. J. Phys. Chem. 43, 139-146.

BOTTINGA Y. and WEILL D. F. (1972) The viscosity of magmatic silicate liquids: a model for calculation. Amer. J. Sci. $272,438-475$.

Fontana E. H. and Plummer W. A. (1979) A viscositytemperature relationship for glass. J. Amer. Ceram. Soc. 62, 367-369.

HUNOLD V. K. and BRUCKNeR R. (1979) Physikalische Eigenschaften und strucktureller Feinbau von Natrium-Alu- minosilicatglasern und -Schmelzen. Glastechnische Berichte 53, 149-161.

LiLliE H. R. (1939) High temperature viscosities of soda-silica glasses. J. Amer. Ceram. Soc. 22, 367-374.

MCMILlan P., PIRIOU B. and NAVRotSKY A. (1982) A Raman spectroscopic study of glasses along the joins silicacalcium aluminate silica-sodium aluminate and silica-potassium aluminate. Geochim. Cosmochim. Acta 46, 20212038.

MeILING G. S. and Uhlmann D. R. (1967) Crystallization and melting kinetics of sodium disilicate. Phys. Chem. Glasses 8, 62-68.

MYSEN B. O., VIRGO D. and SCARFE C. M. (1980) Relations between anionic structure and viscosity of silicate meltsa Raman spectroscopic study. Amer. Mineral. 65, 690-710.

MYSEN B. O., VIRGO D. and SEIFERT F. A. (1982) The structure of silicate melts: Implications for chemical and physical properties of natural magmas. Rev. Geophys. Space Phys. 20, 353-383.

MYSEN B. O., VIRGO D. and SEIFERT F. A. (1985) Relationships between properties and structure of aluminosilicate melts. Amer. Mineral. 70, 88-105.

Nayrotsky A., Peraudeau G., McMillan P. and CouTURES J-P. (1982) A thermochemical study of glasses and crystals along the joins silica-calcium aluminate and silicasodium aluminate. Geochim. Cosmochim. Acta 46. 20392047.

RICHET P. (1984) Viscosity and configurational entropy of silicate melts. Geochim. Cosmochim. Acta 48, 471-483.

RICHET P. and BotTinga Y. (1984) Anorthite, andesine. wollastonite, diopside, cordierite and pyrope: thermodynamics of melting, glass transitions, and properties of the amorphous phases. Earth Planet. Sci. Lett. 67, 415-432.

RiEBLING E. F. (1966) Structure of sodium aluminosilicate melts containing at least 50 mole $\% \mathrm{SiO}_{2}$ at $1500^{\circ} \mathrm{C} . J$. Chem. Phys.

Seifert F., Mysen B. O. and Virgo D. (1981) Quantitative determination of proportions of anionic units in silicate melts. Carnegie Inst. Wash. Yearb. 80, 301-302.

SEIFERT F., MYSEN B. O. and VIRGO D. (1982) Three-dimensional network melt structure in the systems $\mathrm{SiO}_{2}$ $\mathrm{NaAlO}_{2}, \mathrm{SiO}_{2}-\mathrm{CaAl}_{2} \mathrm{O}_{4}$ and $\mathrm{SiO}_{2}-\mathrm{MgAl}_{2} \mathrm{O}_{4}$. Amer. Mineral. 67, 696-718.

TAYLOR M. and BROWN G. E. (1979) Structure of mineral glasses II. The $\mathrm{SiO}_{2}-\mathrm{NaAlSiO}_{4}$ join. Geochim. Cosmochim. Acta 43, 1467-1475. 